\title{
In vitro characterization of Lactobacillus crispatus IP174178 and its live biotherapeutic product for prevention of vaginal infections
}

Caroline Dausset ( $\nabla$ c.dausset@biose.com )

Biose industrie https://orcid.org/0000-0001-8281-1111

Christelle Daniel

IPRAD

Gilles Brami

IPRAD

Adrien Nivoliez

Biose industrie

Research article

Keywords: In vitro, Lactobacillus crispatus IP174178,

Posted Date: October 11th, 2019

DOI: https://doi.org/10.21203/rs.2.15637/v1

License: (a) (i) This work is licensed under a Creative Commons Attribution 4.0 International License.

Read Full License 


\section{Abstract}

Background : Probiotics enhance human well-being. They can be used either as a preventive approach to maintain the microbiota or as an add-on treatment for some diseases. The lactobacilli constitute the predominant vaginal microorganism and have been associated with a beneficial effect in vaginal health by protecting and controlling the vaginal microbiota against bacterial vaginosis, vaginal candidiasis, and urinary tract infection.

Results: We investigated the probiotic properties of the new vaginal Lactobacillus crispatus IP174178 strain isolated from healthy women. Lactobacillus crispatus IP174178 strain was identified by 16S rRNA sequencing and by biochemical characterization. L. crispatus IP174178 is Gram positive, Catalase negative, ADH negative, and an $\mathrm{H} 202(5 \mathrm{mM}$ ) and lactic acid (D-lactate $6 \mathrm{~g} / \mathrm{l}$, L-lactate $3 \mathrm{~g} / \mathrm{l}$ ) producer, with a strong adherence capacity. Its sensitivity to antibiotics was evaluated.

Conclusions: The native strain L. crispatus IP174178 showed natural antagonistic properties against vaginal pathogens ( Gardenerella vaginalis , Candida spp.) which is potentiated in its commercial live biotherapeutic product Physioflor ${ }^{\circledR}$. The L. crispatus IP174178 strain and its live biotherapeutic product Physioflor ${ }^{\circledR}$ can thus be considered a good probiotic candidate for the prevention of vaginal infections.

\section{Background}

The Food and Agriculture Organization of the United Nations (FAO) define probiotics as "live microorganisms which, when administered in adequate amount, confer a health benefit on the host" [1]. These microorganisms exert health promoting properties for both prevention and treatment of a number of human diseases [2,3]. Interest in probiotic bacteria is increasing with the development of adjunct or alternative therapies to traditional treatments. However, the isolation and characterization of new probiotic strains are required for the development of new therapies [4]. Lactobacilli have been commonly used as probiotics for many years since they are easy to "select", cultivate and produce $[5,6]$. Moreover, the use of selected lactobacilli may be effective in restoring the vaginal microbiota and preventing infections [7].

Lactobacilli are typically the prevalent microorganisms in the vaginal microbiota of healthy women of reproductive age. Lactobacillus spp. are commonly identified as the biomarker of a healthy vagina which protect the mucosa against the establishment of pathogenic microorganisms [8]. This protection is mainly due to the ability to adhere to vaginal cells and the secretion of antimicrobial compounds such as $\mathrm{H}_{2} \mathrm{O}_{2}$, organic acids $[9,10]$, and bacteriocins $[11,12]$. The vaginal microbiota has been characterized by the dominance of a single species most closely related to the Lactobacillus spp. (70 \%) mainly L. crispatus (26\%), L. gasseri (6\%), L. jensenii (5\%) or L. iners (34\%) [13-15]. The identification of $L$. crispatus as the most frequently occurring species in white and Asian women is associated with a healthy and stable community $[14,16]$. Moreover, the vaginal colonization by this species has been reported to decrease the risk of bacterial vaginosis [17]. 
Vulvovaginal candidiasis (VVC), bacterial vaginosis (BV), and urinary tract infection (UTI) are the most common urogenital pathologies. These pathologies negatively impact women's quality of life and represent a significant healthcare cost $[18,19]$. Lactobacillus spp., and in particular L. crispatus, are commonly used as probiotics to prevent the development of pathogens, including those responsible for VVC and BV [20,21]. Importantly, the use of probiotics for the development of new therapies requires evaluation of quality of products (linked to the manufacturing process) and a standardization of the characterization techniques used.

In this study, we characterized the L. crispatus IP174178 strain isolated from the vaginal tract of healthy women. The genetic, phenotypic and antimicrobial properties were investigated to determine probiotic potential and safety evaluation of $L$. crispatus IP174178. Moreover, the anti-microbial properties of the manufacturing Live Biotherapeutic Product (LBP)-Physioflor ${ }^{\circledR}$ - containing L. crispatus IP174178 was tested in-vitro against vaginal pathogens.

\section{Results}

L. crispatus IP174178 genomic and biochemical profiles The taxonomic characterization by 16S rDNA sequencing demonstrated that the IP174178 strain had $100 \%$ of sequence identity with the V3-V4 region of L. crispatus. Sequencing of the L. crispatus IP174178 genome allowed the design of specific primers (Table 1) with an efficiency of $97 \%$ as evaluated by qPCR. Their specificity was validated on 12 Lactobacillus spp., three Bifidobacterium spp., five vaginal pathogens and human cells (Table 2). Table 1. Specific primer pair for genomic identification and quantification Primer pair forward CAACAGGCATCCCTAAGTCT reverse CAACGTCTTCAGACCACATC Table 2. Specificity of IP174178 Specific primers Species Name/Ref Average Ct Lactobacillus crispatus IP174178 8,1 Lactobacillus acidophilus T CIP 76.13 ND Lactobacillus brevis T CIP 102806 ND Lactobacillus buchneri T CIP 103023 ND Lactobacillus casei T CIP 103137 ND Lactobacillus crispatus CRBIP24.77 ND Lactobacillus crispatus CIP 103603 ND Lactobacillus crispatus CIP 105002 ND Lactobacillus delbrueckii T CIP 102576 ND Lactobacillus reuteri T CIP 101887 ND Lactobacillus rhamnosus Lcr35® ND Lactobacillus vaginalis T CIP 105932 ND Lactobacillus zeae T CIP 103253 ND Bifidobacterium bacterium Bb-12® ND Bifidobacterium breve T CIP 64.69 ND Bifidobacterium longum CBI0703 ND Candida albicans ATCC10231 ND Candida albicans Clinical strain ND Candida glabrata Clinical strain ND Candida tropicalis Clinical strain ND Gardnerella vaginalis Clinical strain ND Human cells Caco2 ND ND nondetected before 30 cycles of qPCR. This Gram-positive, facultative anaerobic bacterium was characterized by carbohydrate fermentation validating the genotype identification (Table 3). The strain was filed in the National Collection of Microorganism Cultures of the Pasteur Institute under the reference CNCM I-4646. Table 3. Biochemical profile of L. crispatus IP174178 2 APPA + 4 dGAL - 5 ODOC - 6 PheA + 7 ARG - 8 PVATE - 9 BGAL - 10 PYRA - 11 SUCT - 12 TyrA + 13 dGLU + 17 BGLU - 18 dMAL + 19 dMAN + $21 \mathrm{BXYL}-22$ O/129 R + 23 ProA + 26 LIP - 27 AMAN - 30 dMLZ - 31 URE - 33 SAC + 35 dTRE + 36 CIT - 37 BGURi - 40 ILatk - 41 AGLU + 43 dSOR + 44 AGAL - 46 GlyA - 47 dMLT - 50 dRIB - 51 MTE + 52 IGLM - 53 OPS (+) 54 BdFUC - 56 CMT + 59 2KG - 61 ESC - 62 ELLM - 64 dXYL - Antibiotic resistance profile of L. 
crispatus IP174178 The antibiotic resistance profile of L. crispatus IP174178 to the eight antibiotics suggested in the EFSA guidelines and four other common antibiotics is shown in Table 4. Sensitivity was assessed by comparing the zone of inhibition induced by the disk diffusion method and the obtained MIC values to reference breakpoint. L. crispatus IP174178 displayed MIC values lower than the EFSA critical values for six antibiotics - ampicillin, chloramphenicol, clindamycin, erythromycin, gentamicin, tetracycline - and was susceptible to vancomycin $(5 \mu \mathrm{g})$. Two antibiotics, kanamycin and streptomycin, did not affect the viability of the L. crispatus IP174178 at the concentrations recommended by the EFSA (Table 4). Moreover, the IP174178 strain demonstrated resistance to fusidic acid (10 $\mu \mathrm{g})$, metronidazole $(5 \mu \mathrm{g})$ and trimethoprim $(5 \mu \mathrm{g})$. Table 4 . Antibiotics susceptibility of L. crispatus IP174178 strain Disk diffusion method E-test strip method Antimicrobial name Disc concentration Interpretative zone diameters $(\mathrm{mm})$ Diameters $(\mathrm{mm})$ Phenotype MIC $(\mu \mathrm{g} / \mathrm{mL})$ EFSA critical values $(\mu \mathrm{g} / \mathrm{mL})$ Phenotype R S Ampicilin $2 \mu \mathrm{g}$ - - 27,3 S $0.251 \mathrm{~S} 10 \mu \mathrm{g} \leq 12 \geq 16$ 42,7 S Chloramphenicol $30 \mu \mathrm{g} \leq 13 \geq 18$ 38,3 S $0.754 \mathrm{~S}$ Clindamycin $2 \mu \mathrm{g} \leq 8 \geq 1235,7$ S 0.0941 S Erythromycin $15 \mu \mathrm{g} \leq 13 \geq 18$ 37,0 S 0.0471 S Fusidic Acid $10 \mu \mathrm{g} \leq 13 \geq 180,0 \mathrm{R}$-- - Gentamicin $10 \mu \mathrm{g} \leq 12 \geq 13$ 0,0 R $1016 \mathrm{~S}$ Kanamycin $30 \mu \mathrm{g} \leq 13 \geq 180,0 \mathrm{R}$ $>25616$ R Metronidazole $5 \mu \mathrm{g} \leq 14 \geq 180,0 \mathrm{R}$ - - - Streptomycin $10 \mu \mathrm{g} \leq 11 \geq 150,0 \mathrm{R} 3216 \mathrm{R}$ Tetracycline $30 \mu \mathrm{g} \leq 14 \geq 19$ 38,3 S 0.194 S Trimethoprim $5 \mu \mathrm{g} \leq 11 \geq 15$ 0,0 R - - Vancomycin $5 \mu \mathrm{g}$ - - 23,0 S - - 30 $\mu \mathrm{g} \leq 14 \geq 1737,0 \mathrm{~S}$ - - Resistance (R), sensitivity (S), minimum inhibitory concentrations (MIC) Antimicrobial molecule detection Three antimicrobial activities were studied for the native strain (Table 5). No L. crispatus IP174178 alcohol dehydrogenase (ADH) activity was detected. Quantitative analysis by titration showed that the L. crispatus IP174178 produced $5.02 \mathrm{mM} \pm 0.55$ of H2O2. The level of DLactate and L-Lactate produced by L. crispatus IP174178 ranged from $3.10 \mathrm{~g} / \mathrm{l}$ to $5.90 \mathrm{~g} / \mathrm{l}$. The ability to use glucose or glycogen as a carbon source was equivalent for both. Table 5. Physiological activity of L. crispatus IP174178 after 48 hours culture. Activity L. crispatus IP174178 ADH activity - $\mathrm{H}^{2} \mathrm{O}^{2} 5.02 \mathrm{mM}$ \pm 0.55 Lactic acid Glucose D-Lactate : $5.90 \mathrm{~g} / \mathrm{l} \pm 1.62$ (66 \%) L-Lactate : $3.10 \mathrm{~g} / \mathrm{l} \pm 1.01$ (34 \%) Glycogen DLactate : $5.65 \mathrm{~g} / \mathrm{I} \pm 1.96$ (64 \%) L-Lactate : $3.16 \mathrm{~g} / \mathrm{l} \pm 1.04$ (36 \%) Results of ADH activity and H2O2 and lactic acid production were expressed by mean \pm standard deviation between triplicate experiment and negative control. In vitro adhesion to epithelial cells The adhesion of the microorganisms to epithelial cells was quantified. L. crispatus IP174178 showed a significant ability to adhere to Caco-2 and CRL2616 vaginal cells at $\mathrm{MOI} 100$ to $\mathrm{MOI} 0.1$ : > $20 \%$ after 3 hours of incubation. No significant difference in adhesion properties was detected between the two epithelial cell types (Fig 1A). IP174178 immunomodulation The in vitro immunomodulation of PBMCs induced by IP174178 revealed low secretion of anti-inflammatory IL-10 compared to Bifidobacterium longum IPL, the reference antiinflammatory strain of the Lille Pasteur Institute (Fig. 1B). IP174178 induced a slight increase in TNF-a secretion but no significant production of IL-12p70 or IFN- $\gamma$ cytokines compared to the reference proinflammatory Lactococcus lactis IPL. Acid and bile tolerance The native strain and its LBP Physioflor ${ }^{\circledR}$ showed a good resistance to $\mathrm{pH} 2.5, \mathrm{pH} 3.0$ and $\mathrm{pH} 4.0$ for $90 \mathrm{~min}$ (Fig 2A-2B) and tolerance to exposure to $3 \%$ bile salt for $240 \mathrm{~min}$ (Fig 2C-2D) with no impairment of viability. Antimicrobial activity of Lactobacillus crispatus IP174178 and Physioflor ${ }^{\circledR}$ During co-culture the native strain induced a loss of viability of $2.02 \log$ and $2.29 \log$ to C. albicans ATCC $\AA$ 10231TM after respectively $24 \mathrm{~h}$ and $48 \mathrm{~h}$ (Fig $3 \mathrm{~A}$ ). Similarly, a loss of viability of $1.12 \log$ and 1.66 log to clinical C. albicans was observed after 24 and 48 
hours of co-culture (Fig 3B). No significant growth inhibition of C. glabrata was detected after 24 hours of co-culture but after 48 hours a loss of viability of $1.87 \mathrm{log}$ was observed (Fig 3C). Physioflor ${ }^{\circledR}$ induced complete loss of viability of C. albicans ATCC $\circledast 10231 \mathrm{TM}(7.1 \mathrm{log})$, clinical C. albicans $(7.23 \mathrm{log})$ and C. glabrata (7.38 log) after 24 hours of contact (Fig 3A-3B-3C). A significant difference of anti-microbial effect against these three pathogen strains was observed between the native strain and manufactured $\mathrm{L}$. crispatus IP174178 (Physioflor ${ }^{\circledR}$ ). The viability of C. tropicalis was reduced by 1.54 log after $48 \mathrm{~h}$ in contact with L. crispatus IP174178 and by 1.50 log with Physioflor ${ }^{\circledR}$ (Fig 3D). Similar growth inhibitions of $\mathrm{C}$. tropicalis were observed during co-culture with the native strain and the manufacturing product. Loss of viability of G. vaginalis was observed after $24 \mathrm{~h}$ of co-incubation with the native strain and Physioflor ${ }^{\circledR}$ (Fig 3E). Manufactured IP174178 induced a significant effect compared to the native strain on the viability of $\mathrm{G}$. vaginalis at $4 \mathrm{~h}$ of co-culture $(5.75 \log 10(\mathrm{CFU} / \mathrm{ml})$ vs $1.36 \log 10(\mathrm{CFU} / \mathrm{ml}))$. The control pathogen cultures demonstrated that pathogen growth was not impacted by $\mathrm{pH}$ and by additive of Physioflor®.

\section{Discussion}

Probiotics have gained increasing interest in recent years, and their popularity has led to the emergence of many probiotic strains with various applications. However, characterization of the native strain and of their derived products is sometimes poor. Numerous studies have demonstrated the influence of the manufacturing process on bacterial properties, in particular on the stability and the production of molecules of interest. Thus, the correct identification and complete characterization of probiotic strains are essential to guarantee their identity and consequently their safety and proclaimed health benefits [22].

Vaginal microbiota of healthy women is dominated by Lactobacillus spp., which play a key role against pathogen infections [23]. If the microbiota balance is disturbed, pathologies can develop such as bacterial vaginosis. This pathology usually induces dysbiosis with a decreased abundance of lactobacilli. LBP supplementation could restore healthy communities [24].

This is the case for recurrent vaginal infections. The usual drugs are relatively effective to treat recurrent BV and VVC, but probiotic supplementation provides restoration of vaginal communities and thus reduces the risk of infection recurrences $[25,26]$.

The safety assessment including antimicrobial susceptibility is a necessary evaluation to be considered for probiotic application. The immune response induced by L. crispatus IP174178 was evaluated by flow cytometry analysis of cytokine production. IP174178 induced a slight increase in IL-10 and TNF-a secretion and no significant production of the immune mediators IL-12p70 and INF-y cytokines compared to reference strains. The level of INF- $\gamma$ was correlated with the level of IL-12p70 as generally observed for lactobacilli[27]. The cytokine profile of IP174178 on human PBMCs tends to be neutral (cytokine ratio <5) according to Pot et al [28]. So, L. crispatus IP174178 was not associated with inflammatory response, consistently with in vitro and in vivo studies which demonstrate that vaginal lactobacilli are generally 
non-inflammatory $[29,30]$. Commensal and probiotic bacteria play a role in maintaining vaginal homeostasis through several mechanisms to promote antimicrobial defense while not inducing immunomodulation [31].

According to EFSA recommendations, IP174178 antimicrobial susceptibility was determined against 14 antibiotics.L. crispatus IP174178 strain demonstrate a sensitivity to 8 antibiotics tested. As majority of Lactobacillus, IP174178 strain is susceptible to ampicillin, tetracycline, erythromycin and chloramphenicol [32]. Conversely, L. crispatus IP174178 could be associated with metronidazole treatment to eliminate vaginal infections.

The safety assessment of L. crispatus IP174178 strain, isolated from healthy vaginal microbiota, reveals an interesting probiotic potential which induced an in vitro characterization of its probiotic properties. The adherence capability and ability to survive under high acidic conditions are key properties to be considered during probiotic potential evaluation. As several Lactobacillus; L. crispatus IP174178 showed acid and bile salt tolerance which suggest appropriate probiotic application. Moreover, adhesion of probiotic strains to the vaginal epithelium is key event order to prevent the colonization of pathogenic microorganisms by occupying binding sites [33]. Our study showed favorable adhesion to human vaginal and intestinal cells suggesting that IP174178 has capability to adhere to the human epithelium. Similarly, high adherence capability to Caco-2 cells was reported for Lactobacillus strains [34]

Herein, we show that the strain isolated from healthy vaginal microbiota, IP174178, produces both hydrogen peroxide and lactic acid which could contribute to create a hostile environment for the growth and development of pathogenic microorganisms [35]. Indeed, lactic acid has previously been shown to maintain vaginal $\mathrm{pH}$ below $4.5[12,36]$.

Moreover, in vitro,L. crispatus IP1714178 induced a significant loss of viability of the pathogenic strains. L. crispatus IP174178 was selected for its probiotic potential, taxonomy and its anti-Candida properties for a vaginal application. As shown in previous studies, manufacturing processes and large scale production influence the strain properties and have sometimes improving potency [37-39]. The Antimicrobial intrinsic properties of L. crispatus are potentiated by the manufacturing process of Physioflor ${ }^{\circledR}$ especially designed to prevent vaginal infections. After subculture, the Candida spp. studied, except for $C$. tropicalis, demonstrated complete loss of viability after $24 \mathrm{~h}$ of contact with Physioflor ${ }^{\circledR}$. Similarly, Physioflor ${ }^{\circledR}$ was shown to be effective against G. vaginalis within 24 hours.

Because the industrial process impact the intrinsic properties of bacteria, same parameters need to be reevaluated using final product containing probiotic bacteria [38, 39]. In order to evaluate tolerance and efficacy of Physioflor ${ }^{\circledR}$, a clinical trial needs to be carry-out. However, we previously aimed to select and optimize the industrial formulation. The optimization parameters were thus performed by analyzing the bacterial viability, antimicrobial properties and probiotic use.

\section{Conclusions}


In conclusion, our results show that the IP174178 strain of L. crispatusdisplays probiotic capacities: it does not impact the immune system, it is resistant to acid and bile salts; and it boosts antimicrobial activities. The properties of probiotics are strain specific and the quality of the derived products is closely linked to the manufacturing process and to the characterization techniques used.Hence, characterization of the L. crispatus IP174178 strain was important to guarantee the accurate and reliable identity of the probiotic strain. Moreover, the promising results we obtained in in vitro conditions have been validated by a first clinical study showing a preventive effect of Physioflor ${ }^{\circledR}$ administered over four menstrual cycles on recurrent bacterial vaginosis [40]. Overall our studies confirm the safety and the in vitro study confirms the efficacity of $L$ crispatus against several pathogens involved in vulvovaginal infections. Other therapeutic applications of L. crispatus could be considered and would need to be validated by in vitro, in vivo and by clinical trials. Moreover, the mechanism of action involved in anti-microbial activity of $L$. crispatus IP174178 need to be investigated and will be addressed in other publication.

\section{Methods}

\section{Strains and culture conditions}

The L. crispatus IP174178 strainwas inoculated at $10^{6} \mathrm{CFU} / \mathrm{ml}$ in De Man, Rogosa and Sharpe (MRS) broth (BIORAD, Mitry Mory, France). Similarly, LBP Physioflor ${ }^{\circledR}$ (produced by BIOSE industrie, France) containing L. crispatus IP174178 $\left(10^{9} \mathrm{CFU}\right.$ per gram) and several cryoprotectants (including magnesium stearate, milk powder, fructo-oligosaccharide, sodium glutamate, ascorbic acid, sodium thiosulfate, glucose, brewer's yeast and polysorbate 80 ) was inoculated at $10^{6} \mathrm{CFU} / \mathrm{ml}$ in MRS broth. Both subcultures were incubated for 48 hours at $37^{\circ} \mathrm{C}$. The pathogenic strain, Candida albicans ATCC ${ }^{\circledR}$ $10231^{\mathrm{TM}}$, and three clinical vaginal strains $C$. albicans,C. glabrata and $C$. tropicalis [38], were inoculated at $10^{6} \mathrm{CFU} / \mathrm{ml}$ in Sabouraud Dextrose Broth (bioMerieux, Marcy l'Etoile, France) and incubated at $25^{\circ} \mathrm{C}$

for 48 h. Gardnerella vaginalis ATCC ${ }^{\circledR} 14018^{\mathrm{TM}}[38]$ was inoculated at $10^{6} \mathrm{CFU} / \mathrm{ml}$ in brain heart infusion (BHI) supplemented with yeast extract $(1 \% \mathrm{w} / \mathrm{v})$, maltose $(0.1 \% \mathrm{w} / \mathrm{v})$, glucose $(0.1 \% \mathrm{w} / \mathrm{v})$, and horse serum ( $10 \% \mathrm{v} / \mathrm{v}$ ) with $5 \%$ of $\mathrm{CO}_{2}$ (SIGMA-ALDRICH St-Quentin-Fallavier, France) at $37^{\circ} \mathrm{C}$ for $48 \mathrm{~h}$. For immunomodulation test, Bifidobacteriumlongum IPL and Lactococcus lactis MG1363 strains were grown in anaerobic stationary phase at $37^{\circ} \mathrm{C}$ in MRS supplemented with $0.05 \%$ L-cysteine-hydrochloride (SIGMA-ALDRICH, St-Quentin-Fallavier, France) and at $30{ }^{\circ} \mathrm{C}$ in M17 medium supplemented with $0.5 \%$ glucose respectively [27].

\section{Quantification of cultivable cells}

The cultivable lactobacilli cells were enumerated by a plate count method on MRS agar (bioMerieux, Marcy l'Etoile, France) incubated under anaerobic conditions at $37^{\circ} \mathrm{C}$ for $72 \mathrm{~h}$. Sabouraud 
Chloramphenicol agar plates (bioMerieux, Marcy l'Etoile, France) were incubated $120 \mathrm{~h}$ at $25^{\circ} \mathrm{C}$ for the Candida strains and Gardnerella agar plates incubated at $37^{\circ} \mathrm{C}$ for $72 \mathrm{~h}$ for the Gardenerella strains. Serial dilutions of the microbial suspensions were assessed in sterile water with a limit of detection at 10 $\mathrm{CFU} / \mathrm{ml}[38,41]$. All assays were performed in triplicate.

\section{Genomic and biochemical profile}

Genomic DNA was extracted from colonies isolated after $48 \mathrm{~h}$ of culture on MRS agar plates (GenoScreen, Lille, France). An optimized and standardized DNA extraction protocol was used for bacterial DNA extraction from fecal samples (GenoScreen, Lille, France). A bead-beating method employing glass and zirconia beads was added based on the QIAamp DNA stool Mini Kit (Qiagen, Courtaboeuf, France). DNA quality was checked by $2 \%$ agarose gel and quantified with the Qubit ${ }^{\circledR}$ dsDNA BR assay Kit (Life Technologies, USA).

Microbial diversity was determined by GenoScreen using Metabiote ${ }^{\circledR}$ protocole which targeting V3 and V4 16S rRNA hypervariable regions (Metabiote ${ }^{\circledR}$, GenoScreen, Lille, France).

The biochemical profile was obtained from colonies isolated after $48 \mathrm{~h}$ of culture on MRS agar plates by automated reading of CBC cards in VITEK II compact equipment (bioMerieux, Marcy l'Etoile, France). All assays were performed in triplicate.

\section{Genetic identification}

L. crispatus IP174178 specific primers were designed with a home-made BioPerl software using Primer3 and their specificity checked using Fuzznuc $[42,43]$. Their specificities were further checked using Blast software $[44,45]$ and on 12 lactobacilli, three bifidobacteria, five vaginal pathogens and human cells by classic PCR using HotStarTaq Master Mix kit (Qiagen, Courtaboeuf, France) and Mastercycle thermocycler (Eppendorf, Le Pecq, France). All DNA were extracted from $1.10^{9} \mathrm{CFU} / \mathrm{ml}$ sample using Precellys 24 (Bertin Technologies, Rockville, US) for cell lysis and UltraClean Microbial DNA Isolation Kit (MoBio Laboratories, Carlsbad, USA) according to manufacturers' recommendations. The quality of total DNA samples was checked by DNA NanoChips using Agilent DNA 6000 Nano Reagents kit on the Agilent 2100 Bioanalyser (Agilent Technologies, Santa Clara, US). Primers efficiency was determined by qPCR on 10X DNA serial dilutions using QuantiFast SYBR Green PCR kit and Rotor Gene Q (Qiagen, Courtaboeuf, France) following the supplier's instructions. 


\section{Antibiotic resistance}

To determine the safety of L. crispatus, the European Food Safety Authority (EFSA) recommends evaluating susceptibility to the following antibiotics: ampicillin, chloramphenicol, clindamycin, erythromycin, gentamicin, kanamycin, streptomycin, tetracycline, and four other common antibiotics.

The antibiotic resistance profile of the L. crispatus IP174178 strain was determined by E-test gradient strips (bioMerieux, Marcy l'Etoile, France) and disk diffusion method (bioMerieux, Marcy l'Etoile, France) onto LSM medium recommended by the International Organization of Standardization (ISO)/International Dairy Federation (IDF) and composed of a mix of $90 \%$ of Iso-sensitest (Oxoid, Dardilly, France) and $10 \%$ of MRS agar (bioMerieux, Marcy l'Etoile, France) [46]. Inoculum was prepared by picking L.crispatus IP174178 colonies into sodium chloride peptone buffer (bioMerieux, Marcy l'Etoile, France), and turbidity was adjusted to yield $1 \mathrm{McF}$ arland (around $3.10^{8} \mathrm{UFC} / \mathrm{mL}$ ). The agar surface was inoculated by using a swab dipped in cell suspension. One E-test strip or five discs were added on the agar media surface, then the plates were incubated at $37^{\circ} \mathrm{C}$ for $72 \mathrm{~h}$. The minimum inhibitory concentrations (MIC) were determined from the inhibition ellipse that intersected the scale on the strip according to the manufacturer's instructions. The L.crispatus IP174178 resistant-profile was determined according to EFSA Guidelines. Zone diameters were measured at the point at which there was prominent reduction of growth and pinpoint microcolonies at the edge.

The breakpoints for testing lactobacilli are not reported in the European Committee on Antimicrobial Susceptibility Testing (EUCAST) guidelines, or by the CLSI (M-45). Hence our interpretation of the results was based on the breakpoint values suggested by Charteris et al. [47]. For undefined antibiotics, the sensitive profile was defined by an inhibition zone $>0 \mathrm{~mm}$.

\section{In vitro adhesion to epithelial cells}

Adhesion capacity of L. crispatus IP174178 strain was determined according to Nivoliez et al. approach [38]. Two human cell lines were used: colon carcinoma cell line Caco-2 [48] and normal vaginal epithelial cells (VK2/E6E7 ATCC-CRL-2616) [49]. Briefly, CRL-2616 cell line was cultured in keratinocyte SFM Combination (LIFE TECHNOLOGIE, Villebon-sur-Yvette, France) and Caco-2 cells were inoculated in Dulbecco modified Eagle's medium (DMEM) supplemented with $10 \%$ inactivated fetal calf serum (LIFE TECHNOLOGIE, Villebon-sur-Yvette, France). Cells were seeded at $2.5 .10^{5}$ Caco-2 cells/well and 3.5.10 5 CRL-2616 cells/well in 24-well plate and cultured at $37^{\circ} \mathrm{C}$ with a $5 \% \mathrm{CO} 2$ in air atmosphere. At confluence, cells were treated during $1 \mathrm{~h}$ and $3 \mathrm{~h}$ at $37^{\circ} \mathrm{C}$ under $5 \% \mathrm{CO} 2$ with L. crispatus IP174178 washed after overnight growth to obtain 1000,100, 10 and 1 final multiplicities of infection (MOI). Then, the cells were then washedto remove non- or loosely adherent bacteria. Cells were then lysed and 
resuspended in sterile water. Viable bacteria were quantified by plating serial dilutions onto MRS agar plates. All adhesion analyses were performed in three independent experiments with technical triplicates.

\section{Cytokine quantification}

This step was performed by the BLIM entity of the Lille Pasteur Institute (France) as described previously by Breton et al. [50]. The experimental protocol was approved by BLIM's institution committees (INSERM, CNRS and Institut Pasteur de Lille). In accordance with the abovementioned committees, blood samplings were collected by authorized staff upon approved agreement of healthy informed volunteers (signed consents). Briefly, bacterial strain cultures were washed and resuspended in phosphate buffered saline (PBS) supplemented with $20 \%$ glycerol (SIGMA-ALDRICH, St-Quentin-Fallavier, France) to obtain $1.10^{9} \mathrm{CFU} / \mathrm{mL}$.

Human Peripheral Blood Mononuclear Cells (PBMCs) isolated from blood of four healthy donors were treated with $10 \mu \mathrm{l}$ of 3-unit McFarland, to obtain bacterium-to-cell ratio of approximately 10:1,for 24 h at $37{ }^{\circ} \mathrm{C}$ [27]. Negative control cells were treated with PBS supplemented with $20 \%$ glycerol (nonstimulated). Then the anti-inflammatory interleukin IL10, and pro-inflammatory cytokines IL-12p70, TNF-a and INF- $\gamma$ were measured by ELISA in culture supernatants using BD Pharmingen ${ }^{\mathrm{TM}}$ antibody pairs (BD Biosciences, San Jose, Ca, USA) according to the manufacturer's instructions. All the results were obtained from the mean of PBMC results and compared with the control conditions without $L$. crispatus IP174178.

\section{Acid and bile tolerance}

According to Nivoliez et al. protocol [38] the L. crispatus IP174178 acid tolerance was evaluated using gastric juice at $\mathrm{pH} 3.0$ and $\mathrm{pH} 2.5$. Bile tolerance was assed in MRS medium containing $3 \%$ of bile salts. Gastric juice and bile solutions were inoculated with $1.10^{8} \mathrm{CFU} / \mathrm{ml}$ of a 48 -h culture of IP174178 in a final volume of $10 \mathrm{ml}$. The residual viability was determined by plating serial dilutions onto MRS agar plates at T0, T45 and T90 for acid tolerance test and at T0, T60, T120, T180, and T240 min for bile tolerance test.

All tolerance tests were performed in triplicate.

\section{Detection of antimicrobial molecules}

To investigate the antimicrobial molecules secreted by L. crispatus IP174178 the approach described previously by Nivoliez et al. [38] was applied with some modifications.

The bacterial arginine deaminase activity was determined using Diatab kit (EUROBIO, Courtaboeuf, France) according to the manufacturer's instructions. 
Hydrogen peroxide production was quantified by colorimetry using an enzymatic peroxidase reaction. After $48 \mathrm{~h}$ of anaerobic incubation in BHI broth (MRS interacts with reagents) at $37^{\circ} \mathrm{C}, \mathrm{L}$. crispatus IP174178 cells were exposed one hour to aerobic conditions.

One mililitre of supernatant was added to a solution containing $100 \mu \mathrm{l}$ of 4-aminoantipyrine (4 mg.mL-1 solution of 4-amino-2, 3-dimethyl-1-phenyl-3-pyrazolin-5-one, SIGMA-ALDRICH, St-Quentin-Fallavier, France), $40 \mu$ l of water saturated phenol, $60 \mu$ l of horseradish Peroxidase type VI-A (500 U.ml-1, SIGMAALDRICH, St-Quentin-Fallavier, France) and phosphate buffer KH2PO4/K2HPO4 (0.1M, pH7, SIGMAALDRICH, St-Quentin-Fallavier, France). After 5 mins of reaction, the absorbance was measured by spectrometry at $505 \mathrm{~nm}$ and reported on standard range of hydrogen peroxide (1 to $20 \mathrm{mM}$, SIGMAALDRICH, St-Quentin-Fallavier, France) diluted in BHI broth [51].

To measure the lactic acid production, L. crispatus IP174178 was inoculated at $1.10^{6} \mathrm{CFU} / \mathrm{ml}$ in MRS broth containing a only glucose or glycogen carbon source at $20 \mathrm{~g} / \mathrm{l}$ and incubated at $37^{\circ} \mathrm{C}$ for $48 \mathrm{~h}$. The culture was then centrifuged at $9.000 \mathrm{~g}$ for $15 \mathrm{mins}$. The lactic acid production was measured in the supernatant using a specific enzymatic kit (Enzytec TM d/I-Lactic acid kit, BIO-CONTROL SYSTEM, Nieuwerkerk aan den IJssel, Netherlands).

\section{Vaginal pathogen growth inhibition}

The pathogens $C$. albicans and G.vaginalis [38], and the probiotic strain were subcultured for $48 \mathrm{~h}$ in their respective media and then mixed in similar ratios $\left(1.10^{8} \mathrm{CFU} / \mathrm{ml}\right.$ each). During the $48 \mathrm{~h}$ of co-incubation, viable pathogen cells were enumerated by plating serial dilutions and $\mathrm{pH}$ was measured in sample aliquots (numeric probe Mettler Toledo MA235 - InLab413). The controls corresponded to pathogens incubated with the additive of Physioflor ${ }^{\circledR}$ and without L. crispatus IP174178 in culture medium with adjusted $\mathrm{pH}$. Because $\mathrm{G}$. vaginalis is sensitive to $\mathrm{pH}$, a culture medium $\mathrm{pH}$ adjusted before inoculation with $\mathrm{HCl} 0.1 \mathrm{M}$ (DUTSCHER, Brumath, France) was used as growth control. Medium adjusted at $\mathrm{pH} 4$ and $\mathrm{pH} 5$ were evaluated for all pathogens, and medium at $\mathrm{pH} 4.5$ was also tested with $G$. vaginalis. Each assay was performed in triplicate.

\section{Statistical analysis}

Statistical analyses were performed using a one-way ANOVA test followed by Bonferroni correction for growth experiments and were carried out using GraphPad Prism 5 software (www.graphpad.com/prism) at several significance levels $(* p<0.05 ; * \star p<0.01 ; * \star \star p<0.001)$.

\section{Declarations}

\section{Ethics approval and consent to participate}




\section{Consent for publication}

Not applicable

\section{Availability of data and materials}

All data generated and analyzed during this study are included in the published article.

\section{Competing interest}

Adrien NIVOLIEZ and Caroline DAUSSET have an institutional affiliation with the company which manufactures the product.

Christelle DANIEL and Gilles BRAMI have an institutional affiliation with IPRAD which markets the product.

\section{Funding}

IPRAD company provided financial support in the form of salaries and analysis, this commercial affiliation didn't influence the study.

\section{Author's contributions}

AN analyzed data managed the project and contribute in writing the manuscript. GB was a contributor of project management and in reviewing the manuscript. ChD was a contributor in writing the manuscript. CaD performed several experimentations and was a major contributor in writing the manuscript.

\section{Acknowledgments}

We wish to thank Gaëlle Castel, Aurélie Lacalmontie and Amandine Pralus for their assistance. Thanks to BLIM team in particular Benoit Foligne for his cooperation.

\section{References}

1. Food and Agriculture Organization Guidelines for the evaluation of probiotics in food. FAO/WHO Working Group report on drafting guidelines for the evaluation of probiotics in food London. 2002. 
2. Martín R, Miquel S, Ulmer J, Kechaou N, Langella P, Bermúdez-Humarán LG. Role of commensal and probiotic bacteria in human health: a focus on inflammatory bowel disease. Microb Cell Fact. 2013;12:71.

3. Martín R, Miquel S, Ulmer J, Langella P, Bermúdez-Humarán LG. Gut ecosystem: how microbes help us. Benef Microbes. 2014;5:219-33.

4. Presti I, D’Orazio G, Labra M, La Ferla B, Mezzasalma V, Bizzaro G, et al. Evaluation of the probiotic properties of new Lactobacillus and Bifidobacterium strains and their in vitro effect. Appl Microbiol Biotechnol. 2015;99:5613-26.

5. Kovachev SM, Vatcheva-Dobrevska RS. Local Probiotic Therapy for Vaginal Candida albicans Infections. Probiotics and Antimicrobial Proteins. 2015;7:38-44.

6. Xie HY, Feng D, Wei DM, Mei L, Chen H, Wang X, et al. Probiotics for vulvovaginal candidiasis in nonpregnant women. Cochrane Database Syst Rev. 2017;11:CD010496.

7. Reid G, Dols J, Miller W. Targeting the vaginal microbiota with probiotics as a means to counteract infections. Curr Opin Clin Nutr Metab Care. 2009;12:583-7.

8. Ma B, Forney LJ, Ravel J. The vaginal microbiome: rethinking health and diseases. Annual review of microbiology. 2012;66:371-389.

9. Amabebe E, Anumba DOC. The Vaginal Microenvironment: The Physiologic Role of Lactobacilli. Front Med (Lausanne). 2018;5. doi:10.3389/fmed.2018.00181.

10. Kovachev S. Defence factors of vaginal lactobacilli. Crit Rev Microbiol. 2017;:1-9.

11. Milioni C, Martínez B, Degl'Innocenti S, Turchi B, Fratini F, Cerri D, et al. A novel bacteriocin produced by Lactobacillus plantarum LpU4 as a valuable candidate for biopreservation in artisanal raw milk cheese. Dairy Science \& Technology. 2015;95:479-494.

12. Borges S, Silva J, Teixeira P. The role of lactobacilli and probiotics in maintaining vaginal health. Archives of Gynecology and Obstetrics. 2013;289:479-489.

13. Ravel J, Gajer P, Abdo Z, Schneider GM, Koenig SSK, McCulle SL, et al. Vaginal microbiome of reproductive-age women. Proceedings of the National Academy of Sciences. 2011;108 Supplement 1:4680-4687.

14. Petrova MI, Lievens E, Malik S, Imholz N, Lebeer S. Lactobacillus species as biomarkers and agents that can promote various aspects of vaginal health. Frontiers in Physiology. 2015;6. doi:10.3389/fphys.2015.00081.

15. Albert AYK, Chaban B, Wagner EC, Schellenberg JJ, Links MG, van Schalkwyk J, et al. A Study of the Vaginal Microbiome in Healthy Canadian Women Utilizing cpn60-Based Molecular Profiling Reveals 
Distinct Gardnerella Subgroup Community State Types. PLoS ONE. 2015;10:e0135620.

16. Verhelst R, Verstraelen H, Claeys G, Verschraegen G, Van Simaey L, De Ganck C, et al. Comparison between Gram stain and culture for the characterization of vaginal microflora: Definition of a distinct grade that resembles grade I microflora and revised categorization of grade I microflora. BMC Microbiol. 2005;5:61.

17. van de Wijgert JHHM, Borgdorff $H$, Verhelst $R$, Crucitti T, Francis $S$, Verstraelen $H$, et al. The Vaginal Microbiota: What Have We Learned after a Decade of Molecular Characterization? PLoS ONE. 2014;9. doi:10.1371/journal.pone.0105998.

18. Hanson L, VandeVusse L, Jermé M, Abad CL, Safdar N. Probiotics for Treatment and Prevention of Urogenital Infections in Women: A Systematic Review. J Midwifery Womens Health. 2016;61:339-55.

19. Mittu B, Kaur B, Balgir PP. Bacterial Vaginosis. Clinical Microbiology: Open Access. 2015. doi:10.4172/2327-5073.1000e124.

20. Srinivasan S, Hoffman NG, Morgan MT, Matsen FA, Fiedler TL, Hall RW, et al. Bacterial communities in women with bacterial vaginosis: high resolution phylogenetic analyses reveal relationships of microbiota to clinical criteria. PLoS ONE. 2012;7:e37818.

21. Fredricks DN, Fiedler TL, Marrazzo JM. Molecular Identification of Bacteria Associated with Bacterial Vaginosis. New England Journal of Medicine. 2005;353:1899-911.

22. Ayala DI, Cook PW, Franco JG, Bugarel M, Kottapalli KR, Loneragan GH, et al. A Systematic Approach to Identify and Characterize the Effectiveness and Safety of Novel Probiotic Strains to Control Foodborne Pathogens. Front Microbiol. 2019;10. doi:10.3389/fmicb.2019.01108.

23. Ravel J, Brotman RM. Translating the vaginal microbiome: gaps and challenges. Genome Med. 2016;8. doi:10.1186/s13073-016-0291-2.

24. Lepargneur J-P. Lactobacillus crispatus as biomarker of the healthy vaginal tract. Ann Biol Clin (Paris). 2016;74:421-7.

25. Bagnall P, Rizzolo D. Bacterial vaginosis: A practical review. Journal of the American Academy of PAs. 2017;30:15.

26. Denning DW, Kneale M, Sobel JD, Rautemaa-Richardson R. Global burden of recurrent vulvovaginal candidiasis: a systematic review. Lancet Infect Dis. 2018;18:e339-47.

27. Foligne B, Nutten S, Grangette C, Dennin V, Goudercourt D, Poiret S, et al. Correlation between in vitro and in vivo immunomodulatory properties of lactic acid bacteria. World J Gastroenterol. 2007;13:236-43. 
28. Pot B, Foligné B, Daniel C, Grangette $C$. Understanding immunomodulatory effects of probiotics. Nestle Nutr Inst Workshop Ser. 2013;77:75-90.

29. Smith SB, Ravel J. The vaginal microbiota, host defence and reproductive physiology. J Physiol. 2017;595:451-63.

30. Aldunate M, Srbinovski D, Hearps AC, Latham CF, Ramsland PA, Gugasyan R, et al. Antimicrobial and immune modulatory effects of lactic acid and short chain fatty acids produced by vaginal microbiota associated with eubiosis and bacterial vaginosis. Frontiers in Physiology. 2015;6. doi:10.3389/fphys.2015.00164.

31. Witkin SS, Linhares IM. Why do lactobacilli dominate the human vaginal microbiota? BJOG: An International Journal of Obstetrics \& Gynaecology. 2017;124:606-11.

32. Kirtzalidou E, Pramateftaki P, Kotsou M, Kyriacou A. Screening for lactobacilli with probiotic properties in the infant gut microbiota. Anaerobe. 2011;17:440-3.

33. Santos CMA, Pires MCV, Leão TL, Hernández ZP, Rodriguez ML, Martins AKS, et al. Selection of Lactobacillus strains as potential probiotics for vaginitis treatment. Microbiology. 2016;162:1195-207.

34. Duary RK, Rajput YS, Batish VK, Grover S. Assessing the adhesion of putative indigenous probiotic lactobacilli to human colonic epithelial cells. Indian J Med Res. 2011;134:664-71.

35. Aroutcheva A, Gariti D, Simon M, Shott S, Faro J, Simoes JA, et al. Defense factors of vaginal lactobacilli. American Journal of Obstetrics \& Gynecology. 2001;185:375-379.

36. Miller EA, Beasley DE, Dunn RR, Archie EA. Lactobacilli Dominance and Vaginal pH: Why Is the Human Vaginal Microbiome Unique? Front Microbiol. 2016;7:1936.

37. Grześkowiak $Ł$, Isolauri E, Salminen S, Gueimonde M. Manufacturing process influences properties of probiotic bacteria. The British Journal of Nutrition. 2011;105:887-894.

38. Nivoliez A, Camares O, Paquet-Gachinat M, Bornes S, Forestier C, Veisseire P. Influence of manufacturing processes on in vitro properties of the probiotic strain Lactobacillus rhamnosus Lcr $35{ }^{\circledR}$. Journal of Biotechnology. 2012;160:236-41.

39. Sanders ME, Klaenhammer TR, Ouwehand AC, Pot B, Johansen E, Heimbach JT, et al. Effects of genetic, processing, or product formulation changes on efficacy and safety of probiotics. Annals of the New York Academy of Sciences. 2014;1309:1-18.

40. Bohbot JM, Daraï E, Bretelle F, Brami G, Daniel C, Cardot JM. Efficacy and safety of vaginally administered lyophilized Lactobacillus crispatus IP 174178 in the prevention of bacterial vaginosis recurrence. J Gynecol Obstet Hum Reprod. 2018;47:81-6. 
41. Ben-David A, Davidson CE. Estimation method for serial dilution experiments. Journal of Microbiological Methods. 2014;107:214-221.

42. Rice P, Longden I, Bleasby A. EMBOSS: the European Molecular Biology Open Software Suite. Trends in genetics: TIG. 2000;16:276-277.

43. Rozen S, Skaletsky H. Primer3 on the WWW for general users and for biologist programmers. Methods in Molecular Biology (Clifton, NJ). 2000;132 Bioinformatics Methods and Protocols:365-386.

44. Altschul SF, Gish W, Miller W, Myers EW, Lipman DJ. Basic local alignment search tool. J Mol Biol. 1990;215:403-10.

45. Park Y, Sheetlin S, Ma N, Madden TL, Spouge JL. New finite-size correction for local alignment score distributions. BMC Research Notes. 2012;5:286.

46. 14:00-Interantional Organization of Standarization/International Dairy Federation17:00. ISO 10932:2010 Milk and milk products - Determination of the minimal inhibitory concentration (MIC) of antibiotics applicable to bifidobacteria and non-enterococcal lactic acid bacteria (LAB). ISO. 2010.

47. Charteris WP, Kelly PM, Morelli L, Collins JK. Gradient diffusion antibiotic susceptibility testing of potentially probiotic lactobacilli. J Food Prot. 2001;64:2007-14.

48. Pinto M, Robine-Leon S, Appay M., Kedinger M, Triadou N, Dussaulx E, et al. Enterocyte-like differentiation and polarization of the human colon carcinoma cell line Caco-2 in culture. Biology of the cell. 1983.

49. Fichorova RN, Rheinwald JG, Anderson DJ. Generation of papillomavirus-immortalized cell lines from normal human ectocervical, endocervical, and vaginal epithelium that maintain expression of tissuespecific differentiation proteins. Biology of Reproduction. 1997.

http://www.biolreprod.org/content/57/4/847.long. Accessed 18 Dec 2016.

50. Breton J, Daniel C, Vignal C, Body-Malapel M, Garat A, Plé C, et al. Does oral exposure to cadmium and lead mediate susceptibility to colitis? The dark-and-bright sides of heavy metals in gut ecology. Scientific Reports. 2016;6:19200.

51. Batdorj B, Trinetta V, Dalgalarrondo M, Prévost H, Dousset X, Ivanova I, et al. Isolation, taxonomic identification and hydrogen peroxide production by Lactobacillus delbrueckii subsp. lactis T31, isolated from Mongolian yoghurt: inhibitory activity on food-borne pathogens. Journal of Applied Microbiology. 2007;103:584-593.

\section{Figures}


A

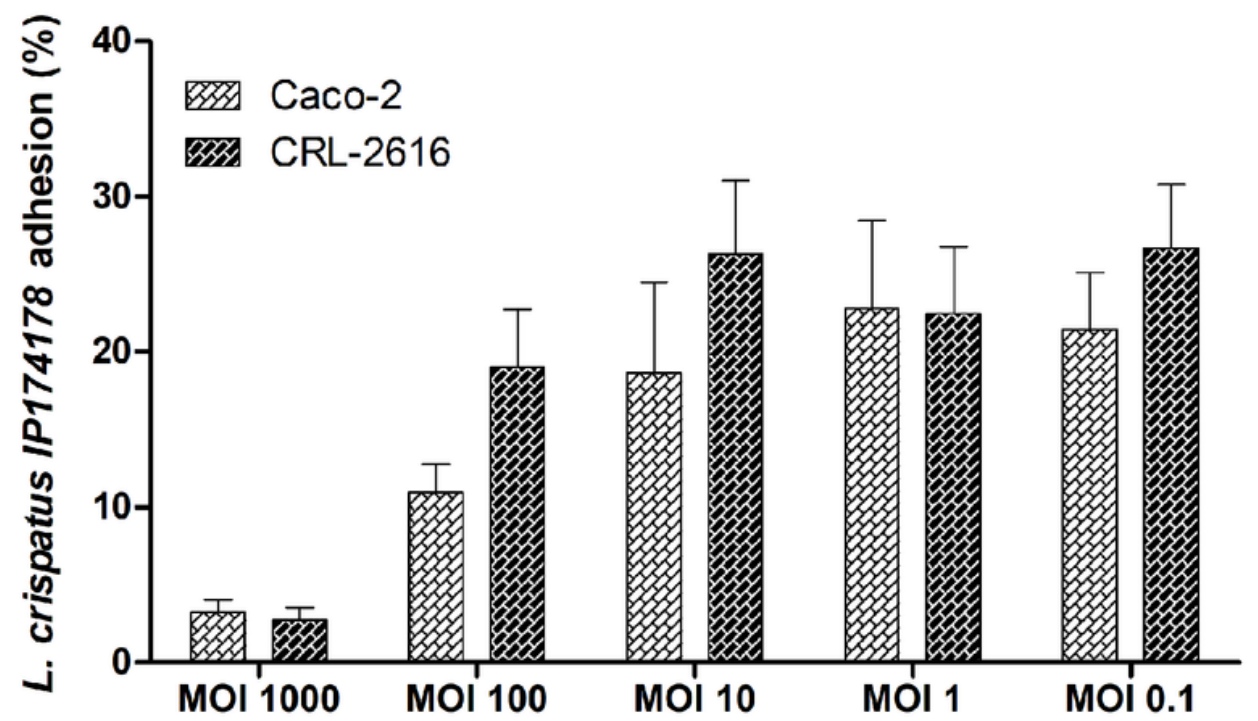

B
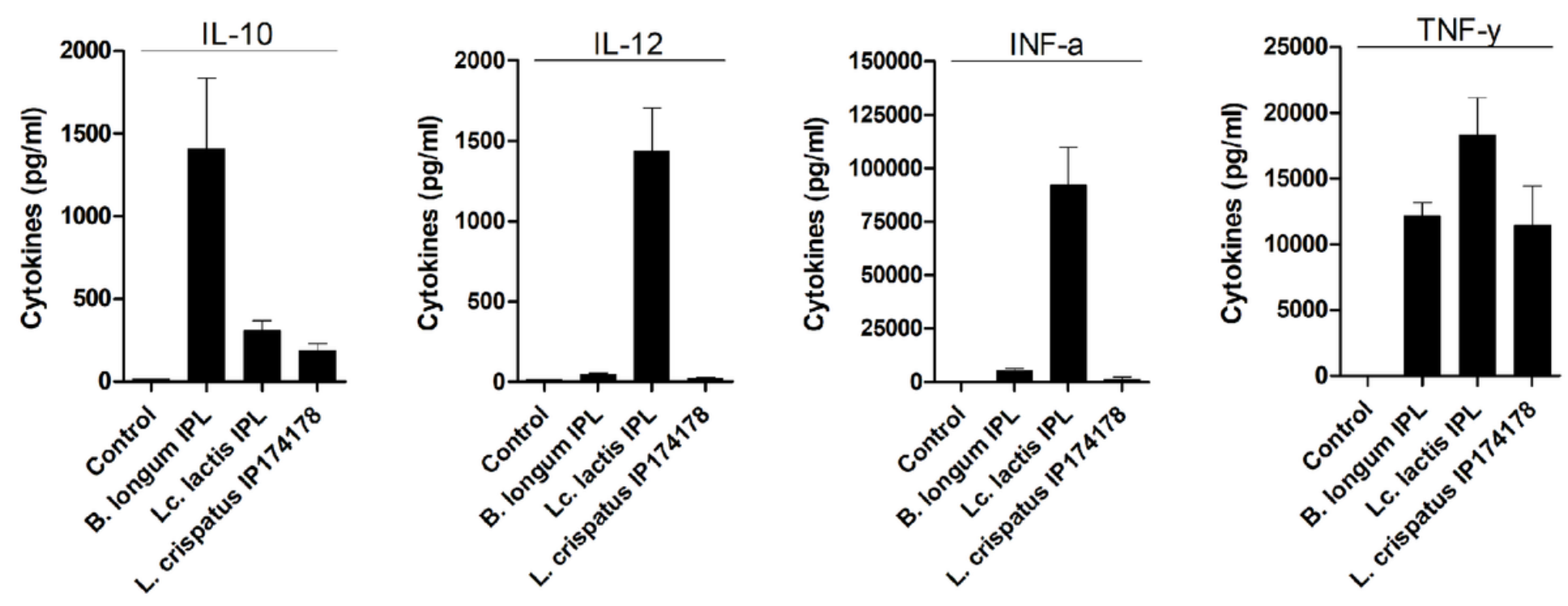

Figure 1

Adhesion and immunomodulation properties of L. crispatus IP174178. (A) Viable adhering L. crispatus IP174178 after 3 hours of contact with Caco-2 or CRL-2616 at multiplicity of infection (MOI) $0.1,1,10$, 100 and 1000. Percentage of adhering bacteria were calculated compared to the initial inoculum. (B) Cytokine secretion by PBMC human cells exposed to L. crispatus IP174178, and as positive control exposed to anti-inflammatory B. longum IPL and pro-inflammatory L. lactis IPL, compared to non-treated sample as negative control cells. The concentration of IL-10, IL-12p70, INF- $y$ and TNF-a was quantified by flow cytometry test. The experiments were performed in triplicate and the mean of results are expressed with standard deviations. 
A

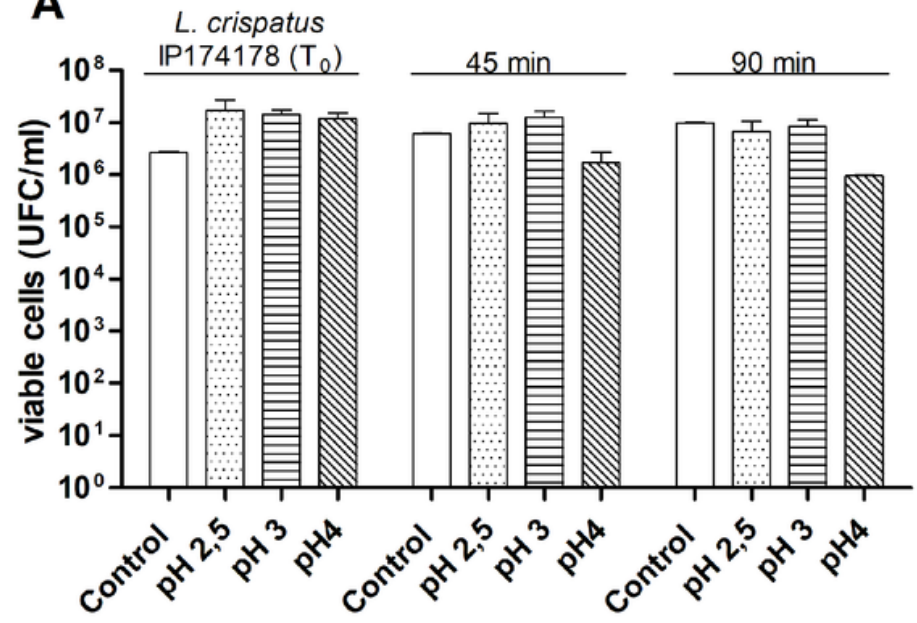

C

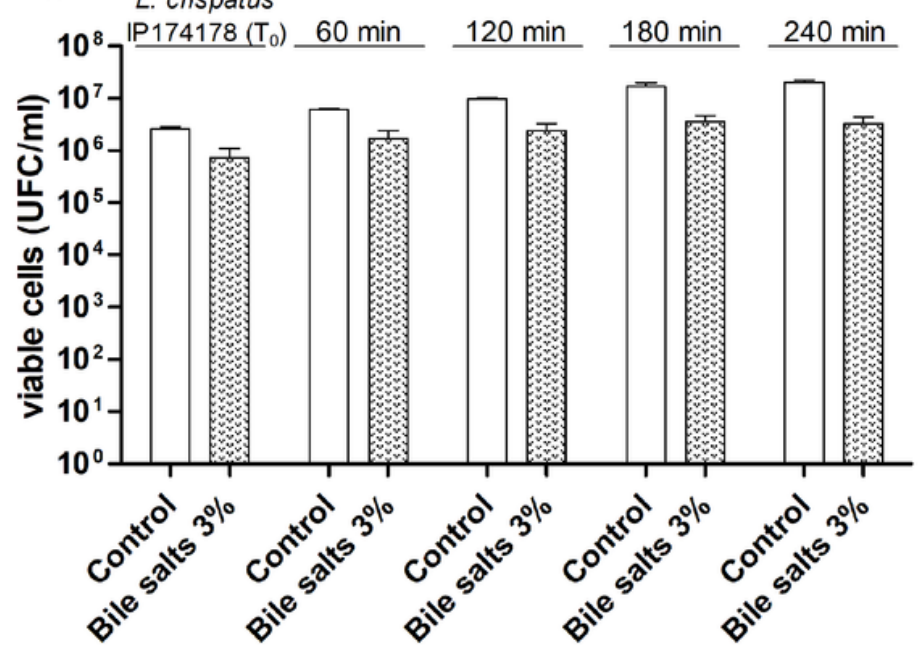

B

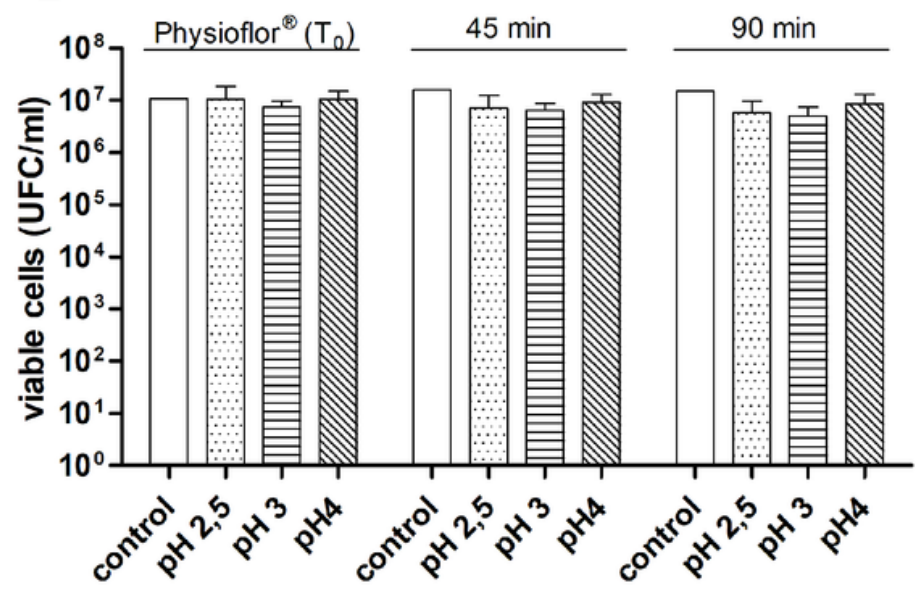

D

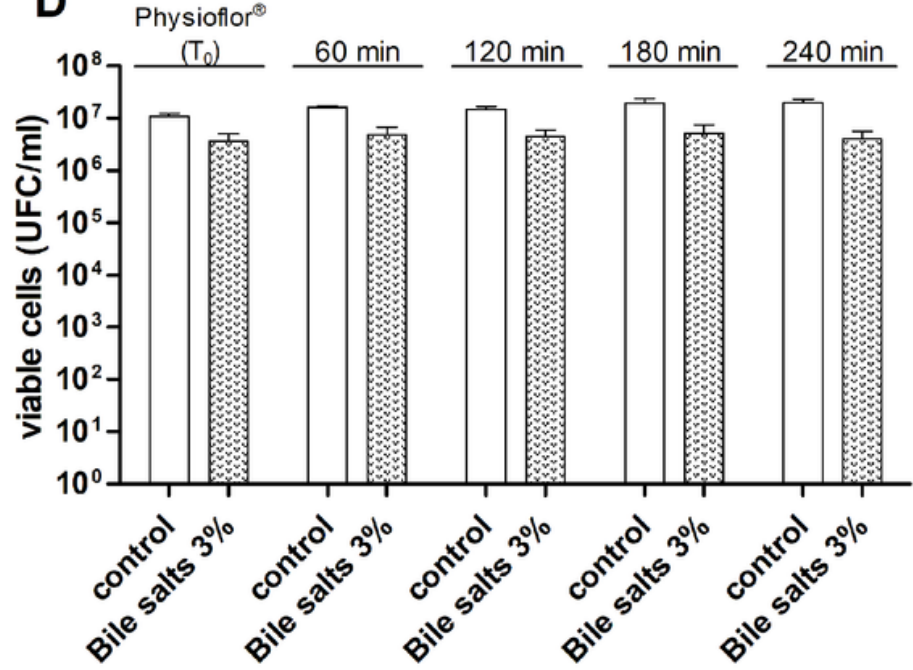

Figure 2

Acid and bile tolerance of L. crispatus IP174178. Quantification of viable L. crispatus cells resistant to pH 2.5, $\mathrm{pH} 3.0, \mathrm{pH} 4.0$ and bile salts (3 \%) of Lactobacillus crispatus IP174178. Experiments were performed in triplicate and the mean of results are expressed with standard deviations. 
A

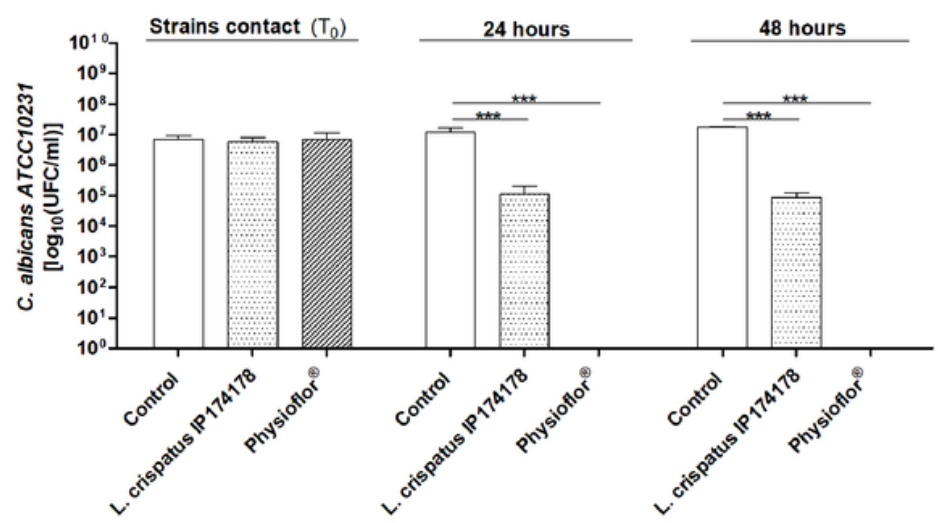

B

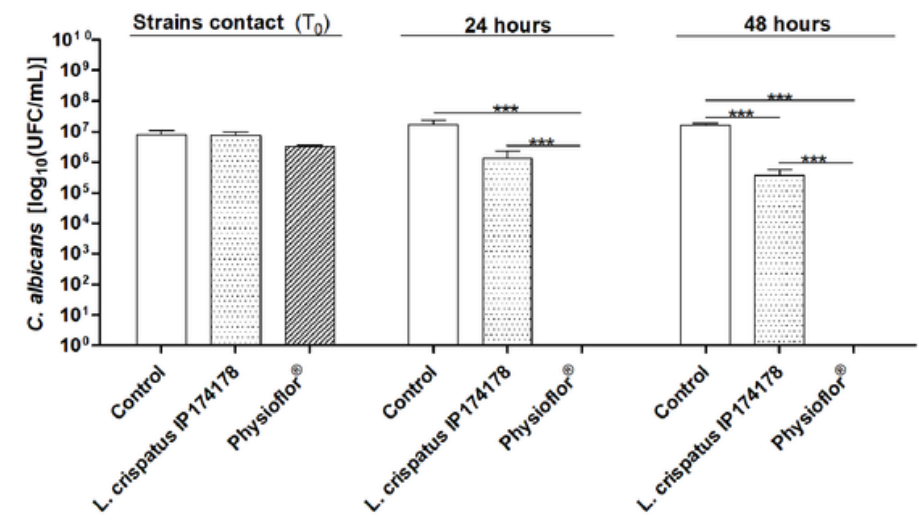

C

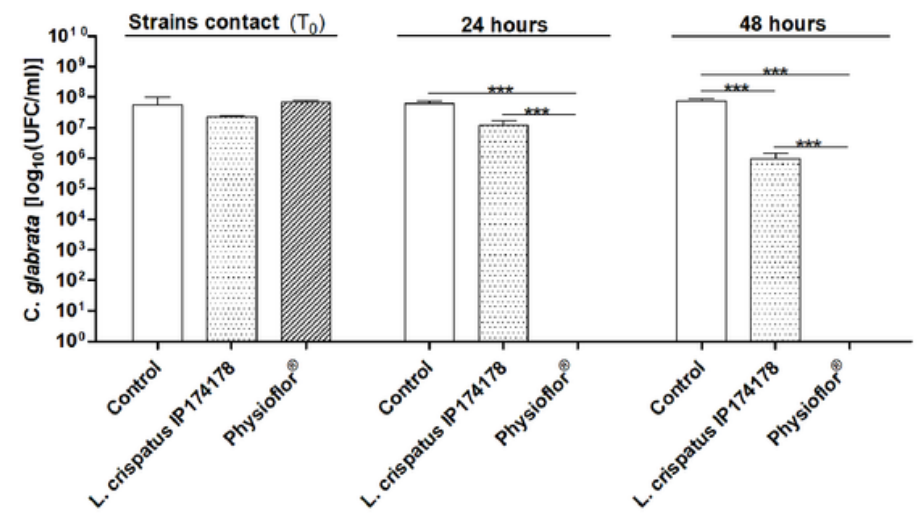

D

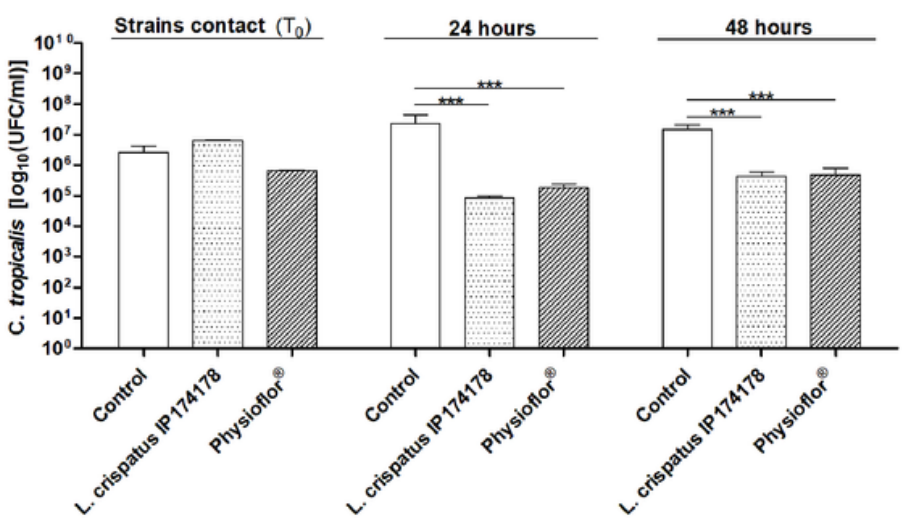

E

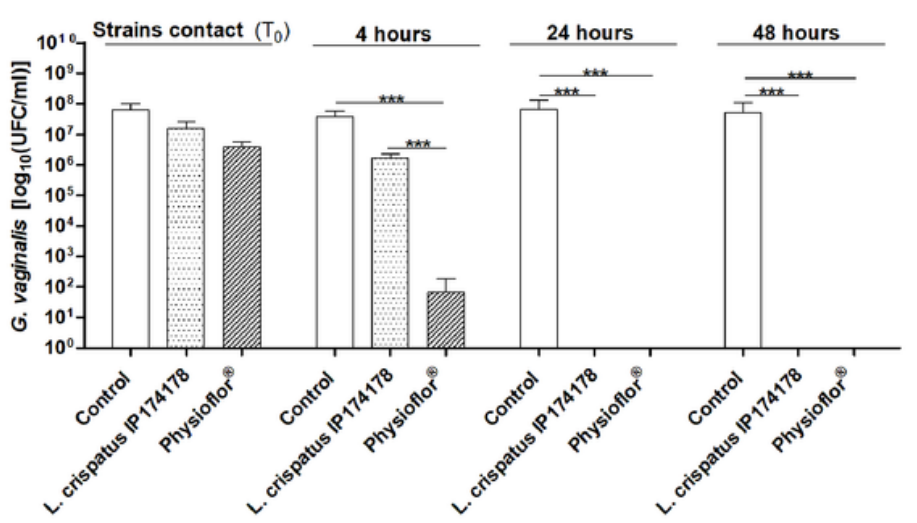

Figure 3

Anti-microbial activity of L. crispatus IP174178 and Physioflor ${ }^{\circledR}$. (A) Viability of C. albicans ATCC $\AA$ 10231TM, (B) clinical C. albicans, (C) C. glabrata, (D) C. tropicalis and (E) G. vaginalis during 24 and 48 hours of co-incubation with L. crispatus IP174178 or its derived product Physioflor ${ }^{\circledR}$. The control experiments, with additive of Physioflor ${ }^{\circledR}$ and without probiotic strains, were carried out at pH 4.0 and pH 5.0. Data were obtained from three independent triplicate experiments, ${ }^{\star} p<0.05$, ${ }^{\star \star} p<0.01$, $* \star \star p<0.001$ (one-way ANOVA test and Bonferroni correction). 